\title{
Regulatory Submission Unique Identifier
}

National Cancer Institute

\section{Source}

National Cancer Institute. Regulatory Submission Unique Identifier. NCI Thesaurus. Code C70869.

A unique identifier assigned to a submittion by the regulatory authority. Submission serial number, volume number, electronic folder, or file name are used as identifiers. 